\title{
Chemically Inducible Inactivation of Protein Synthesis in Genetically Targeted Neurons
}

\author{
Hyun-Soo Je, ${ }^{1 \star}$ Yuan Lu, ${ }^{2 \star}$ Feng Yang, ${ }^{1}$ Guhan Nagappan, ${ }^{1}$ Jianzheng Zhou, ${ }^{1}$ Zhihong Jiang, ${ }^{3}$ Kazu Nakazawa, ${ }^{3}$ \\ and Bai $\mathrm{Lu}^{1,2}$ \\ ${ }^{1}$ Section on Neural Development and Plasticity, National Institute of Child Health and Human Development, and ${ }^{2}$ Genes, Cognition, and Psychosis Program \\ and ${ }^{3}$ Mood and Anxiety Program, National Institute of Mental Health, Bethesda, Maryland 20892-3714
}

\section{Introduction}

Synaptic plasticity mediates a variety of physiological functions, including emotional regulation, drug addiction, and learning and memory (Goelet et al., 1986). There are two temporally distinct forms of synaptic plasticity: short-term plasticity, which lasts seconds to minutes, and long-term plasticity, which lasts hours and days (Davis and Squire, 1984). Long-term plasticity differs from the short-term one in its dependence on gene transcription and protein translation. This conclusion, however, is solely based on the use of pharmacological inhibitors, which have various side effects with limited specificity (Sidhu and Omiecinski, 1998; Xiong et al., 2006). For example, the most potent protein synthesis inhibitor, anisomycin, has been shown to elicit relatively specific and strong activation of stress-related p46/54 ${ }^{\text {JNK }}$ and p38 MAPK (Cano and Mahadevan, 1995), which are themselves implicated in synaptic plasticity (Bol-

Received March 13, 2009; revised April 20, 2009; accepted April 23, 2009. This research was supported by the Intramural Research Program of the National Institutes of Health. We thank Drs. Newton Woo, Angela Mabb, Thomas Newpher, and Keri Martinowich for helpful discussions and critical comments on the manuscript, ARIAD Pharmaceuticals for AP20187, and Regeneron Pharmaceuticals for the recombinant BDNF.

${ }^{*}$ H.S.J. and Y.L. contributed equally to this work.

Correspondence should be addressed to Dr. Bai Lu, Porter Neuroscience Research Center, Laboratory of Cellular and Synaptic Neurophysiology, National Institute of Child Health and Human Development, National Institutes of Health, 35 Lincoln Drive, MSC 3714, Building 35, Room 1C1004 Office, Bethesda, MD 20892-3714. E-mail: bailu@mail.nih.gov.

DOI:10.1523/JNEUROSCI.1280-09.2009

Copyright $\odot$ 2009 Society for Neuroscience $\quad$ 0270-6474/09/296761-06\$15.00/0 shakov et al., 2000). In addition, cycloheximide, one of the most commonly used protein synthesis inhibitors, has significant toxic side effects, including DNA damage, teratogenesis, and other nonspecific effects (EmmanouilNikoloussi et al., 2007). Furthermore, these pharmacological approaches cannot inhibit protein synthesis in a celltype- or region-specific manner. Thus, there is a demand for developing chemical genetic approach to inhibit protein synthesis in neurons.

Here, we describe a chemically inducible system that allows rapid and reversible inhibition of protein synthesis in specific cells. This system uses the double-stranded (ds) RNA-dependent protein kinase [or protein kinase $\mathrm{R}$ (PKR)], which reversibly phosphorylates the $\alpha$ subunit of eukaryotic initiation factor-2 (eIF $2 \alpha)$ to control protein synthesis in eukaryotic cells (Klann and Dever, 2004). The kinase activity of PKR is very low at rest, but is significantly induced upon binding of its dsRNAbinding domains to dsRNAs during viral infection, leading to dimerization and activation of the kinase, and subsequent protein synthesis inhibition ( $\mathrm{Wu}$ and Kaufman, 1997). To establish a genetically engineered protein synthesis inhibition system, we used a FKBP12based, chemically inducible dimerization system (id-PKR) to control the dimerization of the PKR kinase domain (Inoue et al., 2005). This system allows specific inhibition of eIF $2 \alpha$-mediated protein synthesis selectively in presynaptic or postsynaptic neurons that express the system, in an inducible and reversible manner. We have tested the utility of the system in two different models: dendritic spines and filopodia of hippocampal neurons, and late-phase long-term potentiation (L-LTP) in acute hippocampal slices. Our results suggest that in each particular model, protein synthesis in either presynaptic or postsynaptic neuron is uniquely involved in specific aspects of synaptic regulation. The inducible $\mathrm{PKR}$ system may serve as a useful tool to study the role of protein synthesis in neuronal functions in vitro and in cognitive behaviors in vivo.

\section{Materials and Methods}

Transfection and protein analysis in HEK293 cells and cortical neurons. HEK293T cells were transfected at $85-90 \%$ confluency by Lipofectamine 2000 (Invitrogen) using the DNA constructs (pd1EGFP-N1, pCV-HA-FKBP$\mathrm{PKR}$ ) as indicated in figure legends. The ratio between pd1EGFP-N1 and pCV-HA-FKBPPKR was 1:4 in cotransfection. Cells were transfected for $6 \mathrm{~h}$ and treated with drugs after $24 \mathrm{~h}$ as indicated in figure legends. Following treatment, cells were washed once with PBS, lysed in the homogenization buffer $(10 \%$ glycerol, $50 \mathrm{~mm}$ Tris-HCl, pH 7.5, $150 \mathrm{~mm} \mathrm{NaCl}$, $1 \%$ NP-40, $1 \%$ Triton X-100, and $1 \mathrm{~mm}$ EDTA), and centrifuged at $13,000 \times g$ for 20 $\min$ at $4^{\circ} \mathrm{C}$ to remove insoluble material. Estimated protein concentration was measured by Bio-Rad protein assay for protein analysis by Western blotting. Rat cortical neurons prepared from embryonic day 18 were transfected 
with pEGFP-N1 alone or in combination with pCV-HA-FKBP-PKR by nucleofection following the manufacturer's protocol (Amaxa/ Lonza). After 7-10 d in vitro, neurons were treated with different drugs as indicated in figure legends for indicated time intervals and processed for Western analysis as described above for the HEK293T cells. A total of $15 \mu \mathrm{g}$ of protein/lane was resolved on a $4-12 \%$ Bis-Tris NuPAGE (Invitrogen), transferred onto a 0.2 $\mu \mathrm{m}$ PVDF membrane, blocked with 5\% nonfat dry milk (Bio-Rad) in TBST for $1 \mathrm{~h}$, and incubated overnight with primary antibody in $0.5 \%$ milk-TBST (1:3000 mouse anti-GFP, Covance; 1:2000 mouse anti-transferrin receptor, Zymed Laboratories). Following washes, the membrane was incubated with 1:20,000 dilution of anti-mouse IgG-HRP (Piercenet/Thermoscientific) for $1 \mathrm{~h}$. The bands were visualized using the Millipore's Immobilon Western chemiluminescent HRP substrate. Bands were captured in a linear range and analyzed by densitometric analysis using ImageJ version $1.40 \mathrm{~g}$.

Hippocampal neuronal cultures, transfection, and spine density analysis. Rat primary hippocampal neuronal cultures were plated on poly-D-lysine-coated coverslips at a density of 75,000 cells per coverslip for imaging as described previously (Ji et al., 2005). For some experiments, cultures were treated with AP20187 $(1 \mu \mathrm{M})$ for $15 \mathrm{~min}$ before BDNF (a gift from Regeneron Pharmaceuticals) treatment. Dissociated primary hippocampal neurons, grown in culture for $7 \mathrm{~d}$, were transfected with GFP or together with FKBP-PKR system by the calcium phosphate method. Neurons were observed $14 \mathrm{~d}$ after the transfection. Confocal images were obtained using a Zeiss LSM510 confocal microscope (40×, NA 1.30). Optical serial sections of $0.5 \mu \mathrm{m}$ were taken through the cells and reconstructed with maximum projection. The densities of filopodia and of spines were measured. Dendritic protrusions with lengths between 1 and $5 \mu \mathrm{m}$ were divided into two categories: spines-stubby, thin, mushroom- and branched-shaped spines previously described in the literature; and filopodia-thin, uniform-caliber, headless protrusions from the dendrites. Spine or filopodium density (number per $10 \mu \mathrm{m}$ segment) was calculated by dividing the number of spines or filopodia by the length of the segment in micrometers and multiplied by 10 . Each segment was counted as an individual observation $(n=1)$.

Sindbis viral construct, production of viruses, and brain injection. FKBP vector was obtained from ARIAD Pharmaceuticals. The FKBP12 domain was mutated, with a single amino acid substitution (Phe36Val or F36V) that allows specific binding to AP20187 with subnanomolar concentration (Clackson et al., 1998). The binding affinity of AP20187 to the mutant protein is 1000 -fold higher than that to the original FKBP domain (Clackson et al., 1998). Therefore, AP20187, at the concentration we used in this study, should not bind or induce dimerization of endogenous FKBP domains. id-PKR was created by fusing kinase domain of human
PKR with modified FKBP12 domain tagged with hemagglutinin (HA). To make HAFKBP-PKR-IRES2-GFP, HA-FKBP12-PKR was amplified by PCR and cloned into IRES2GFP vector from Clontech. Sindbis virus was generated using the Sindbis expression system (Invitrogen). The fragments coding for HAFKBP12-PKR-IRES2-GFP were subcloned into SinRep5. Capped RNAs were generated using the Message Machine Kit (Ambion) and electroporated with the DH-BB helper RNA (Invitrogen) into baby hamster kidney-21 (BHK-21) cells. After $36 \mathrm{~h}$, the supernatant was collected and concentrated by differential centrifugation $\left(200,000 \times g\right.$ for $3 \mathrm{~h}$ at $\left.4^{\circ} \mathrm{C}\right)$.

Virus was injected into the hippocampus of adult (8- to 10 -week-old) mice using stereotaxic apparatus, as described previously (Jeromin et al., 2003; Zakharenko et al., 2003) with minor modifications. Mice were anesthetized with a ketamine $(90 \mathrm{mg} / \mathrm{ml}) /$ xylazine (10 $\mathrm{mg} / \mathrm{ml}$ ) mixture by intraperitoneal injection and placed into a stereotactic frame (Stoelting). Two holes were drilled using a dental drill to gain access to the pyramidal cell layer of CA1 or CA3 of the hippocampus. The coordinates for injection were established using the intersection of the sagittal and coronal suture (bregma) as a reference point for the anteriorposterior and lateral coordinates. A 1/32G needle connected to the Hamilton syringe was placed into the hippocampal area CA1 (AP = $-1.7 \mathrm{~mm}, \mathrm{~L}= \pm 1.1, \mathrm{D}=-1.1)$ or $\mathrm{CA} 3(\mathrm{AP}=$ $-1.8, \mathrm{~L}= \pm 2.4, \mathrm{~V}=-2.0$ ) area (Zakharenko et al., 2003). A bolus of the Sindbis virus was slowly injected into both sides of the brain tissue $(0.80 \mu \mathrm{l})$ over a period of $10 \mathrm{~min}$. Because $\mathrm{CA} 1$ area receives inputs from both the ipsilateral and contralateral CA3 neurons, injection of virus into CA3 of both sides could ensure that protein synthesis in all presynaptic CA3 neurons was blocked. The needle was gradually withdrawn over a period of 3-5 min after completion of the injection. The incision was closed with a surgical silk suture (Ethicon). Mice used in this study were maintained in strict accordance with the animal care guidelines of the National Institutes of Health.

Hippocampal slice electrophysiology and immunostaining. Injected mice (8-10 weeks old) were killed 36-48 h after the in vivo injection. After decapitation, brains were rapidly removed, glued onto the plateau of the slicing chamber, and immersed into ice-cold slicing buffer (in mu: $127 \mathrm{NaCl}, 26 \mathrm{NaHCO}_{3}, 1.2$ $\mathrm{KH}_{2} \mathrm{PO}_{4}, 1.9 \mathrm{KCl}, 1.1 \mathrm{CaCl}_{2}, 2 \mathrm{MgSO}_{4}$, and 10 D-glucose) bubbled with $95 \% \mathrm{O}_{2}$ and $5 \% \mathrm{CO}_{2}$. Transverse slices ( $400 \mu \mathrm{M}$ thick) were prepared with a vibrating microtome (NVSLM1, WPI), kept in oxygenated artificial CSF (ACSF; in mм: $127 \mathrm{NaCl}, 26 \mathrm{NaHCO}_{3}, 1.2 \mathrm{KH}_{2} \mathrm{PO}_{4}, 1.9$ $\mathrm{KCl}, 2.2 \mathrm{CaCl}_{2}, 1 \mathrm{MgSO}_{4}$, and $10 \mathrm{D}$-glucose) for $30 \mathrm{~min}$ at $34^{\circ} \mathrm{C}$ and for another $30 \mathrm{~min}$ at $22^{\circ} \mathrm{C}$. After injected slices were identified by fluorescence microscopy, they were transferred to a submersion recording chamber continually perfused with $32^{\circ} \mathrm{C}$ oxygenated ACSF (rate: 2 $\mathrm{ml} / \mathrm{min}$ ). Approximately, $85 \%$ of neurons were virally labeled in CA1 and CA3 area (data not shown). Slices highly transduced (with high density of GFP-labeled neurons) were equilibrated for at least $15 \mathrm{~min}$ before recording.

ACSF-filled glass electrodes (resistance $<1$ $\mathrm{M} \Omega$ ) was positioned in the stratum radiatum of area CA1 for extracellular recording. Synaptic responses were evoked by stimulating Schaffer collaterals with $0.2 \mathrm{~ms}$ pulses with a bipolar tungsten electrode (WPI) once every 15 s. Drug was applied in perfusion buffer. AP20187 (ARIAD) was dissolved in ethanol (1 $\mathrm{mM}$ ) and diluted to a final concentration of 1 $\mu \mathrm{M}$ immediately before perfusion. Slices were perfused for at least $1 \mathrm{~h}$ before recording. The stimulation intensity was systematically increased to determine the maximal field EPSP (fEPSP) slope and then adjusted to yield 40 $60 \%$ of the maximal (fEPSP) slope. Experiments with maximal fEPSPs of $<0.5 \mathrm{mV}$ or with substantial changes in the fiber volley were rejected. After recording of a stable baseline for $20 \mathrm{~min}$, L-LTP was induced by theta burst stimulation (TBS, 12 bursts, each of four pulses at $100 \mathrm{~Hz}$ ). Early-phase LTP (E-LTP) was induced by a weaker theta burst stimulation protocol (four bursts, each of four pulses at $100 \mathrm{~Hz}$ ). The number of tested slices is indicated in brackets. Under each condition, slices prepared from at least four animals were tested.

Acute slices were treated with or without AP20187 $(1 \mu \mathrm{M})$ in oxygenated ACSF for 75 min at $37^{\circ} \mathrm{C}$. Slices were fixed in $4 \%$ paraformaldehyde overnight at $4^{\circ} \mathrm{C}$, washed in PBS-T (PBS $+0.3 \%$ Triton X-100), and blocked overnight in $10 \%$ goat serum and $5 \%$ bovine serum albumin in PBS-T. The free-floating slices were then incubated with primary antibodies (1:1000 mouse anti-GFP, Millipore; 1:500 rabbit anti-eIF2 $\alpha$-P, Assay Designs) in the blocking buffer, washed in PBS-T, and then incubated with fluorophore-conjugated secondary antibodies (Jackson ImmunoResearch Laboratories) at 1:500 or 1:1000 dilution overnight at $4^{\circ} \mathrm{C}$. The stained slices were mounted using GEL/MOUNT (Biomeda) and imaged at $4 \times$ or $40 \times$ using a Zeiss LSM 510 confocal microscope. For each condition, at least three slices from three mice were examined.

\section{Results \\ Inducible inhibition of de novo protein synthesis}

Previous studies indicated that the dimerization of PKR kinase domain is both necessary and sufficient to activate its kinase function (Ung et al., 2001). The dsRNAbinding domain of PKR was replaced with a well established FKBP domain, which could be dimerized upon exposure to a synthetic ligand, AP20187 (Fig. 1A) (Ung et al., 2001; Inoue et al., 2005). We tested whether the drug-induced dimerization activates FKBP-PKR when expressed in HEK293T cells. Phosphorylation of eIF2 $\alpha$, a direct downstream target of PKR, was monitored upon treatment with AP20187 at various concentrations and 


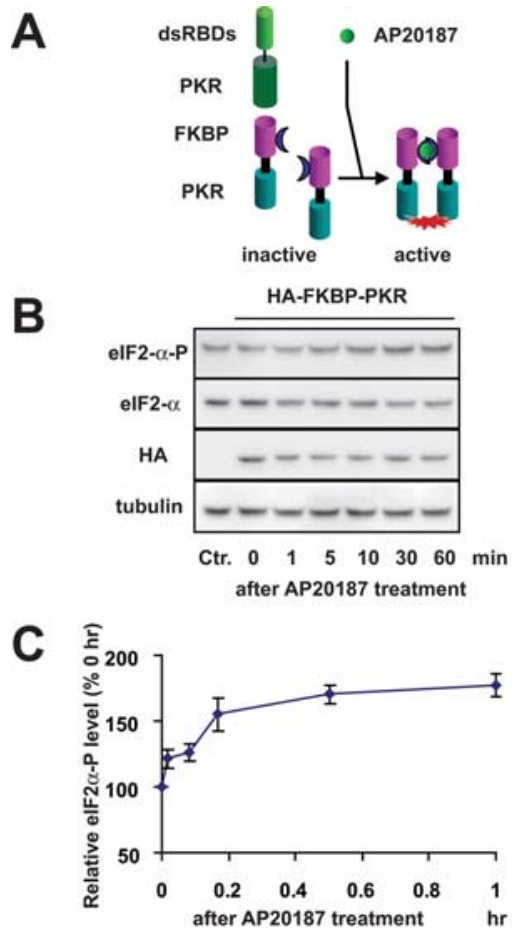

Figure 1. Phosphorylation of elF $2 \alpha$ upon AP20187induced FKBP-PKR dimerization. $\boldsymbol{A}$, Schematic diagrams showing the fusion of PKR kinase domain with AP20187binding domain of FKBP. Application of AP20187 induces the dimerization of the PKR fusion proteins and activates PKR, triggering elF $2 \alpha$ phosphorylation and subsequent de novo protein synthesis inhibition. $\boldsymbol{B}$, Representative blots showing AP20187-induced phosphorylation of elF $2 \alpha$ on Ser51 in HEK293T cells expressing HA-FKBP-PKR. Western blotting was performed using specific antibodies as indicated. The blots were also probed with an anti-tubulin antibody for loading controls (Ctr.). C, Time course of elF $2 \alpha$ phosphorylation induced by AP20817. Multiple blots were quantified $(N=3)$, and elF $2 \alpha-P$ signals at various time points were normalized to that at " 0 " $h$.

durations. Addition of $1 \mu \mathrm{M}$ AP20187 caused rapid eIF2 $\alpha$ phosphorylation (within $5 \mathrm{~min}$ ), which was sustained for $>5$ h (Fig. $1 B, C$; supplemental Fig. $1 B$, available at www.jneurosci.org as supplemental material). The half-maximum response $\left(\mathrm{EC}_{50}\right)$ value for AP20187-induced eIF2 $\alpha$ phosphorylation was $100 \mathrm{nM}$ (supplemental Fig. $1 A$, available at www.jneurosci.org as supplemental material). The inactivation of eIF2 $\alpha$ phosphorylation upon AP20187 withdrawal occurred within $1 \mathrm{~h}$ (supplemental Fig. 1C, available at www.jneurosci.org as supplemental material).

We next investigated whether the dimerization and subsequent activation of PKR inhibited new protein synthesis. Steady-state levels of an exogenously expressed cytosolic protein (destabilized EGFP) and an endogenously expressed membrane protein (Transferrin receptor, TfR) were monitored. In control experi-

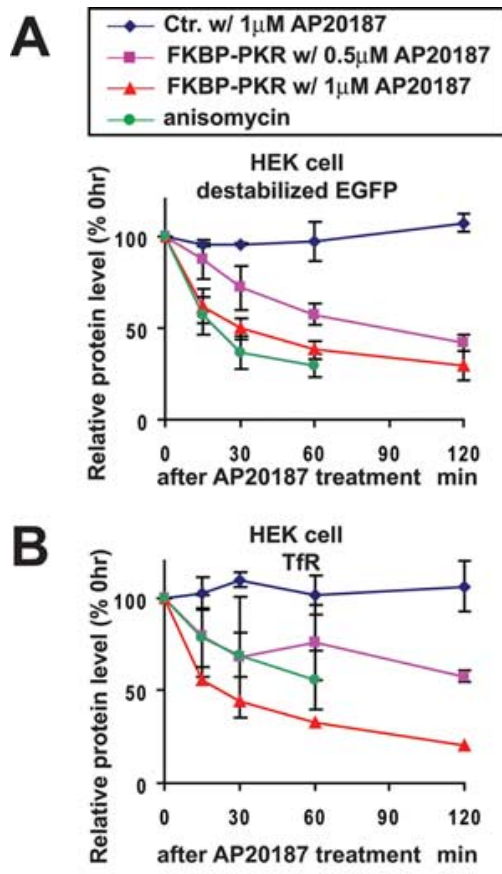

decrease was well correlated with that of eIF2 $\alpha$ phosphorylation, indicating that AP20187 inhibits protein synthesis effectively (Fig. 2A-D; supplemental Fig. 2, available at www.jneurosci.org as supplemental material). Whereas we were able to reduce the levels of marker proteins up to $\sim 70-80 \%$ in HEK cells, only $\sim 40-50 \%$ of reduction was possible in cortical neurons. We attribute such differences to the different transfection efficiency between these two cell types (HEK cells: $>90 \%$ efficiency vs cortical neurons: $\sim 50 \%$ ) rather than the difference in drug efficacy. Together, these results suggest that AP20187-induced dimerization of PKR effectively blocks protein synthesis.

\section{Protein synthesis and BDNF-induced dendritic spine growth}

A number of studies have demonstrated that long-term exposure to the brainderived neurotrophic factor (BDNF) promotes dendritic spine growth in cultured hippocampal neurons (Tyler and PozzoMiller, 2003; Ji et al., 2005). Whereas acute application of BDNF enhances spine motility, it is unclear whether the long-term effect of BDNF on spine growth requires de novo protein synthesis. To determine this, cultured hippocampal neurons were transfected with GFP (to visualize spines) either alone or together with FKBP-PKR. Neurons were then treated with BDNF and/or AP20187 (1 $\mu \mathrm{M})$. In untransfected cells, treatment with BDNF (1 nM) increased the spine density (Fig. $3 A, B$ ) (spine density: $1.65 \pm$ 0.05 in untreated vs $2.86 \pm 0.09$ for BDNF; $p<0.01)$. A similar effect was observed in dendritic filopodia (Fig. $3 A, C$ ) (filopodium density: $0.72 \pm 0.03$ and $0.92 \pm 0.05$ for control and BDNF groups, respectively; $p<0.05)$. Treatment of GFP-control neurons with AP20187 failed to block the BDNF effects (data not shown). In FKBP-PKR-expressing neurons, however, treatment with AP20187 $1 \mathrm{~h}$ before BDNF treatment prevented BDNF regulation of spine growth (Fig. 3B). However, expression of FKBP-PKR alone (without AP20187) did not affect BDNF-mediated spine formation (Fig. 3B). Activation of PKR by AP20187 also prevented the BDNF-induced increase in filopodia (Fig. 3C). Together, these results indicate that the FKBP-PKR system works in mammalian hippocampal neurons, and that new protein synthesis is required for the long-term effect of BDNF on spine growth. 
A
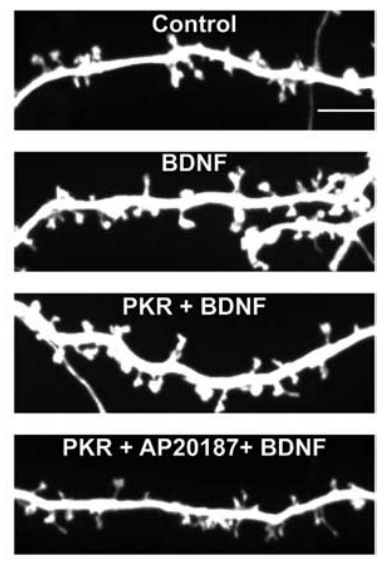

B

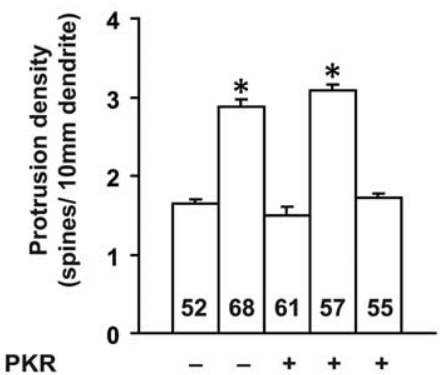

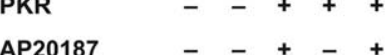
BDNF $\quad-+-++$

C

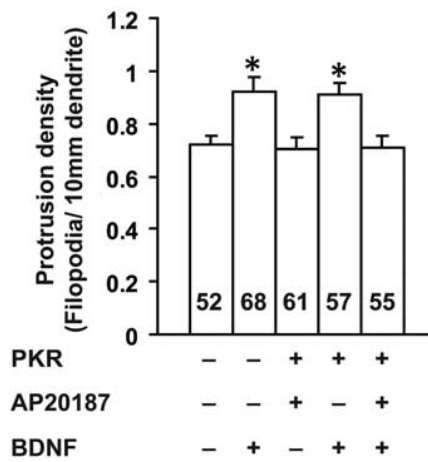

Figure 3. Inhibition of BDNF-mediated spine growth by the FKBP-PKR system. $\boldsymbol{A}$, Sample images of cultured hippocampal neuronal dendrites under various conditions. Rat hippocampal neurons (18-21 d in vitro), transfected with GFP or FKBP-PKR, were fixed after indicated treatments. Scale bar, $10 \mu \mathrm{m}$. B, C, Role of protein synthesis in BDNF regulation of dendritic spines and filopodia. Activation of PKR by AP20187 blocks BDNF-induced changes in spines $(\boldsymbol{B})$ and filopodia (C). At least three independent cultures were examined. Error bars are SEM, and numbers in the columns are the numbers of neurons examined. ${ }^{*} p<0.01$, ANOVA followed by post hoc test.

Protein synthesis and late-phase LTP L-LTP, a cellular model for long-term memory, is thought to require de novo protein synthesis. Treatment of hippocampal slices with protein synthesis inhibitors blocks L-LTP at synapses between Schaffer collateral and CA1 pyramidal neurons (Frey et al., 1988). However, it is
A
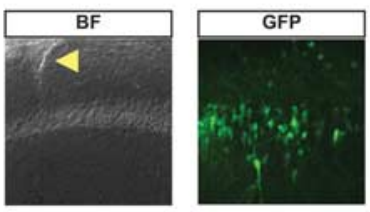

C
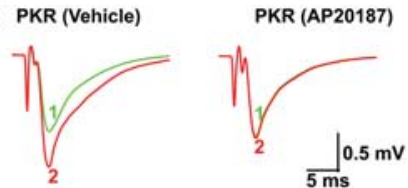

CA1 injection PKR

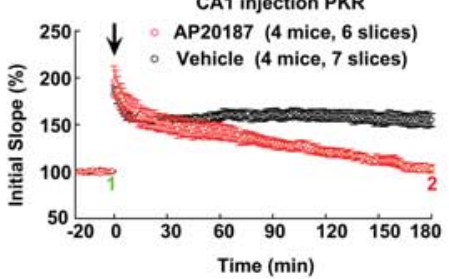

B
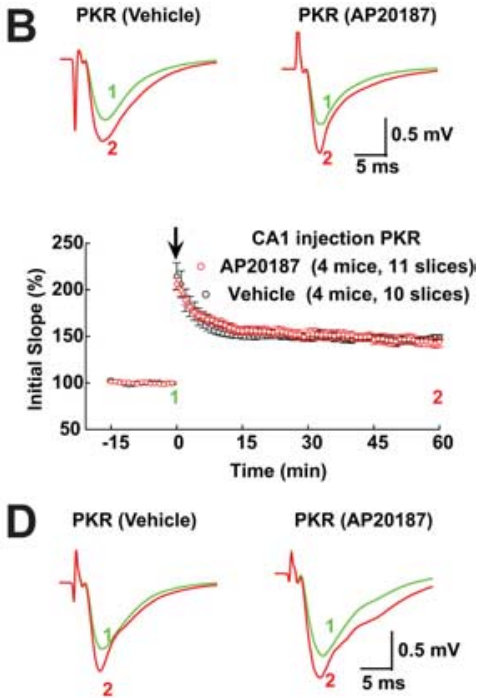

PKR (AP20187)
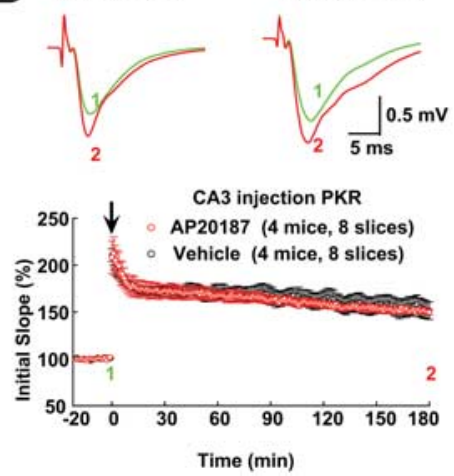

Figure 4. Requirement of protein synthesis in CA1 but not CA3 neurons in hippocampal L-LTP. GFP or FKBP-PKR-GFP Sindbis virus was injected into either $\mathrm{CA} 1$ or CA3 region of hippocampus of 8-week-old C57BL/6 mice. Approximately $36-48 \mathrm{~h}$ after in vivo injection, the animals were killed and hippocampal slices were prepared. $\boldsymbol{A}$, Localization of FKBP-PKR, as indicated by GFP fluorescence, in the CA1 area. The arrowhead indicates the viral injection site. $\boldsymbol{B}$, Normal E-LTP in FKBP-PKR injected slices treated with vehicle or AP20187. Sample traces before ("1") and $3 \mathrm{~h}$ (60 min for B) after (" 2 ") TBS stimulation in this and other figures are shown on top of each figure. $C$, Inhibition of L-LTP by AP20187 in slices expressing FKBP-PKR in CA1. L-LTP was induced by 12-TBS. The difference between vehicle- (155 $\pm 8 \%$, SEM) and AP20187- (104 $\pm 3 \%)$ treated slices at " 2 " is highly significant ( $p<$ $0.0002, t$ test). $D$, Normal L-LTP in AP20187-treated slices expressing FKBP-PKR in CA3.

unclear whether the long-term enhancement of synaptic efficacy depends on protein synthesis in either presynaptic CA3 neurons or postsynaptic CA1 neurons, or both. Therefore, we sought to determine this by using the FKBP-PKR system. We engineered a Sindbis viral vector, HAFKBP-PKR-IRES-EGFP, which independently expresses FKBP-PKR and GFP, and injected the virus into either the CA3 or CA1 region of mouse brain in vivo, using stereotaxic techniques. The GFP fluorescence allowed us to identify the specific regions where HA-FKBP-PKR-IRESEGFP is expressed (Fig. 4A). Double staining with GFP and phospho-eIF $2 \alpha$ specific antibodies confirmed that eIF $2 \alpha$ is phosphorylated in FKBP-PKRexpressing cells upon AP20187 injection (supplemental Fig. 3, available at www. jneurosci.org as supplemental material).

First, we examined the effect of protein synthesis inhibition in CA1. Field recording of EPSPs (fEPSPs) were performed. Application of AP20187 had no effect on the input-output (I/O) curve or pairedpulse facilitation (PPF) in slices express- ing either GFP alone or FKBP-PKR-GFP in the CA1 region, suggesting that the drug is not toxic and inhibition of protein synthesis does not affect basal synaptic properties (supplemental Fig. $4 A-D$, available at www.jneurosci.org as supplemental material). Moreover, E-LTP induced by four bursts of TBS, a form of plasticity independent of protein synthesis (Nguyen and Kandel, 1997), was not affected in slices expressing FKBP-PKRGFP in CA1 (Fig. 4B). However, when L-LTP was induced in CA1 by 12 bursts of theta burst stimulation (12-TBS), treatment with AP20187 severely impaired L-LTP in these slices (Fig. 4C), but not in control slices expressing GFP alone (supplemental Fig. 5, available at www.jneurosci.org as supplemental material). This impairment in L-LTP was similar to slices treated with anisomycin, confirming its dependence on de novo protein synthesis (Pang et al., 2004) (data not shown). Together, these results suggest that inhibition of protein synthesis specifically in the postsynaptic CA1 neurons blocked L-LTP, but not E-LTP.

Finally, we tested whether inhibition 
of protein synthesis in the presynaptic neurons in the CA3 region could block L-LTP in CA1. Remarkably, treatment with AP20187 in slices expressing FKBP-PKR-GFP in CA3 failed to inhibit L-LTP (Fig. 4D), suggesting that presynaptic protein synthesis may not play a major role in maintaining L-LTP. Together, these results indicate that our inducible protein synthesis inhibitor successfully impairs L-LTP by inhibiting postsynaptic, but not presynaptic, de novo protein synthesis.

\section{Discussion}

We have developed a chemical-genetic approach to inducibly inactivate protein synthesis in genetically targeted neuronal populations. Our inducible protein synthesis inactivation system, similar to the chemical genetic inhibition of $\alpha$ CaMKII (Cao et al., 2008), has several advantages over conventional pharmacological approaches for protein synthesis inhibition. First, unlike the commonly used protein synthesis inhibitors (e. g. anisomycin and cycloheximide), the dimerizing drug, AP20187, is essentially less toxic to vertebrate cells. In our hands, incubation with AP20187 at $1 \mu \mathrm{M}$ for $2 \mathrm{~d}$ did not result in any obvious adverse effect (morphology and survival) to the cultured neurons. Second, relatively fast inactivation of eIF2 $\alpha$ phosphorylation upon AP20187 withdrawal enables temporal control of protein synthesis inhibition. Finally, this approach, combined with a specific promoter or expression technique (Kuhlman and Huang, 2008), can be used to target specific areas or cell types, especially, in the nervous system, or even to the presynaptic or postsynaptic component of particular synapses.

Using the inducible PKR system, our study has provided new insights into long-term synaptic modulation in vitro and in vivo. First, whereas the dendritic spine is known to be a place for local protein translation, it remains to be established whether spine growth itself, induced either by high frequency activity or BDNF, requires protein synthesis. We show that the postsynaptic expression and activation of id-PKR is sufficient to block long-term morphological changes in spine growth induced by BDNF. Second, an important, but unresolved issue in the field of long-term synaptic plasticity and memory is whether late-phase LTP in CA1 synapses requires new protein synthesis in presynaptic (CA3) or postsynaptic (CA1) neurons in the hippocampus. Our viral injection experiments demonstrate unequivocally that postsynaptic, but not presynaptic, expression and activation of id-PKR was able to inhibit L-LTP. This result provides a solid support that protein synthesis in CA1 pyramidal cells is critical for memory consolidation ( $\mathrm{Z}$. Jiang and K. Nakazawa, unpublished observation).

Although our id-PKR system allows specific inhibition of eIF $2 \alpha$-mediated protein synthesis in cells expressing the system, only when the drug AP20187 is applied, it remains possible that compensational processes such as over-expression/activation of protein synthesis pathways. Furthermore, the viral transduction technical has the limitations of affecting only distinct number of neurons infected, as well as possible nonspecific effects on the physiology of these cells and tissues. Nevertheless, the id-PKR system may demonstrate more advantages in studying neural development and cognitive behaviors in vivo. Using promoters that drive id-PKR expression in a region-specific or developmentally regulated manner (Lewandoski, 2001), one can study the role of protein synthesis in specific brain regions and/or different developmental stages. As a proof of concept, genetic targeting of id-PKR to the CA1 pyramidal neurons in the hippocampus revealed a critical role of these cells in long-term memory consolidation (Jiang and Nakazawa, unpublished observation). The prospects of using id-PKR in other systems are quite exciting. For example, using the GAD67 promoter to drive id-PKR, one can ask whether protein synthesis in GABAergic interneurons is important for the development of ocular dominance in the visual cortex, or cortical network formation in general (Hensch, 2005). Selective expression of id-PKR in the hippocampus or prefrontal cortex (PFC) could help resolve whether protein synthesis in PFC is required for long-term, remote memory (Touzani et al., 2007). Selective inhibition of protein synthesis in the amygdala or PFC at specific time points during fear memory extinction may also help develop treatments for posttraumatic stress disorders (Parsons et al., 2006).

\section{References}

Bolshakov VY, Carboni L, Cobb MH, Siegelbaum SA, Belardetti F (2000) Dual MAP kinase pathways mediate opposing forms of longterm plasticity at CA3-CA1 synapses. Nat Neurosci 3:1107-1112.
Cano E, Mahadevan LC (1995) Parallel signal processing among mammalian MAPKs. Trends Biochem Sci 20:117-122.

Cao X, Wang H, Mei B, An S, Yin L, Wang LP, Tsien JZ (2008) Inducible and selective erasure of memories in the mouse brain via chemical-genetic manipulation. Neuron 60:353-366.

Clackson T, Yang W, Rozamus LW, Hatada M, Amara JF, Rollins CT, Stevenson LF, Magari SR, Wood SA, Courage NL, Lu X, Cerasoli F Jr, Gilman M, Holt DA (1998) Redesigning an FKBP-ligand interface to generate chemical dimerizers with novel specificity. Proc Natl Acad Sci U S A 95:10437-10442.

Davis HP, Squire LR (1984) Protein synthesis and memory: a review. Psychol Bull 96:518-559.

Emmanouil-Nikoloussi EN, Frangou H, Nikoloussis E, Manthou ME, Papamitsou T, Goula C, Massourides S, Likartsis C, Lazaridis C, Manthos A (2007) Immunohistochemical identification of estrogenic receptors on malignant breast tumor developed after cycloheximide treatment in pregnancy. Reprod Toxicol 24:75-76.

Frey U, Krug M, Reymann KG, Matthies H (1988) Anisomycin, an inhibitor of protein synthesis, blocks late phases of LTP phenomena in the hippocampal CA1 region in vitro. Brain Res 452:57-65.

Goelet P, Castellucci VF, Schacher S, Kandel ER (1986) The long and the short of long-term memory-a molecular framework. Nature 322:419-422.

Hensch TK (2005) Critical period plasticity in local cortical circuits. Nat Rev Neurosci 6:877-888.

Inoue T, Heo WD, Grimley JS, Wandless TJ, Meyer T (2005) An inducible translocation strategy to rapidly activate and inhibit small GTPase signaling pathways. Nat Methods 2:415-418.

Jeromin A, Yuan LL, Frick A, Pfaffinger P, Johnston D (2003) A modified Sindbis vector for prolonged gene expression in neurons. J Neurophysiol 90:2741-2745.

Ji Y, Pang PT, Feng L, Lu B (2005) Cyclic AMP controls BDNF-induced TrkB phosphorylation and dendritic spine formation in mature hippocampal neurons. Nat Neurosci 8:164-172.

Klann E, Dever TE (2004) Biochemical mechanisms for translational regulation in synaptic plasticity. Nat Rev Neurosci 5:931-942.

Kuhlman SJ, Huang ZJ (2008) High-resolution labeling and functional manipulation of specific neuron types in mouse brain by Creactivated viral gene expression. PLoS ONE 3:e2005.

Lewandoski M (2001) Conditional control of gene expression in the mouse. Nat Rev Genet 2:743-755.

Nguyen PV, Kandel ER (1997) Brief theta-burst stimulation induces a transcriptiondependent late phase of LTP requiring cAMP in area $\mathrm{CA} 1$ of the mouse hippocampus. Learn Mem 4:230-243.

Pang PT, Teng HK, Zaitsev E, Woo NT, Sakata K, Zhen S, Teng KK, Yung WH, Hempstead BL, $\mathrm{Lu} B$ (2004) Cleavage of proBDNF by tPA/ 
plasmin is essential for long-term hippocampal plasticity. Science 306:487-491.

Parsons RG, Gafford GM, Helmstetter FJ (2006) Translational control via the mammalian target of rapamycin pathway is critical for the formation and stability of long-term fear memory in amygdala neurons. J Neurosci 26:12977-12983.

Sidhu JS, Omiecinski CJ (1998) Protein synthesis inhibitors exhibit a nonspecific effect on phenobarbital-inducible cytochome $\mathrm{P} 450$ gene expression in primary rat hepatocytes. J Biol Chem 273:4769-4775.

Touzani K, Puthanveettil SV, Kandel ER (2007)
Consolidation of learning strategies during spatial working memory task requires protein synthesis in the prefrontal cortex. Proc Natl Acad Sci U S A 104:5632-5637.

Tyler WJ, Pozzo-Miller L (2003) Miniature synaptic transmission and BDNF modulate dendritic spine growth and form in rat CA1 neurones. J Physiol 553:497-509.

Ung TL, Cao C, Lu J, Ozato K, Dever TE (2001) Heterologous dimerization domains functionally substitute for the double-stranded RNA binding domains of the kinase PKR. EMBO J 20:3728-3737.

Wu S, Kaufman RJ (1997) A model for the double-stranded RNA (dsRNA)-dependent dimerization and activation of the dsRNAactivated protein kinase PKR. J Biol Chem 272:1291-1296.

Xiong W, Kojic LZ, Zhang L, Prasad SS, Douglas R, Wang Y, Cynader MS (2006) Anisomycin activates p38 MAP kinase to induce LTD in mouse primary visual cortex. Brain Res 1085:68-76.

Zakharenko SS, Patterson SL, Dragatsis I, Zeitlin SO, Siegelbaum SA, Kandel ER, Morozov A (2003) Presynaptic BDNF required for a presynaptic but not postsynaptic component of LTP at hippocampal CA1-CA3 synapses. Neuron 39:975-990. 